\title{
ARTÍCULOS
}



FILOLOGÍA CLÁSICA 



\section{IXIÓN Y TÁNTALO, PARADIGMAS TRÁGICOS DE INGRATITUD}

Gema GonZÁlez Ruz

genmagr@hotmail.com

\section{RESUMEN}

El presente artículo pretende ilustrar que los puntos en común, que presentan los personajes míticos de Ixión y de Tántalo, van más allá de que ambos sean condenados eternos en el Hades. Pues estas dos figuras no sólo personifican la ingratitud, ejemplarmente castigada, sino que cumplen a la perfección en sus historias míticas la cadena de acontecimientos ő $\lambda \beta о \varsigma$, кó $о \varsigma$,

Palabras Clave: Mitología clásica; Ingratitud; Ixión; Tántalo.

\section{ReSUMÉ}

Cet article vise à illustrer que les points communs entre les personnages mythiques d'Ixion et de Tantale vont au-delà du fait que tous deux soient des condamnés éternels dans l'Hadès. En effet, non seulement ces deux figures incarnent l'ingratitude, punie de façon exemplaire, mais elles respectent aussi à la perfection l'enchaînement des événe-

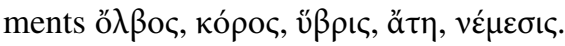

Mots-CLÉs: Mythologie classique; Ingratitude; Ixion; Tantale.

Si nos acercarnos a los personajes míticos de Ixión y Tántalo y pretendemos postular una serie de conexiones entre ellos, podríamos suponer que a priori lo que une a ambos personajes es el haber ofendido a Zeus y, como consecuencia de ello, forman parte de una lista de los condenados eternos en el Hades. Pero un estudio más detenido de los mitos de cada uno de ellos revela que son más numerosos y, sobre todo, más significativos los rasgos comunes que se pueden establecer entre Ixión y Tántalo. En efecto, ambas 
figuras no sólo personifican la ingratitud, ejemplarmente castigada, sino que también uno y otro cumplen a la perfección la cadena de acontecimientos, presente en el pensamiento griego ya desde la poesía arcaica y que alcanza su culminación en la tragedia clásica, que

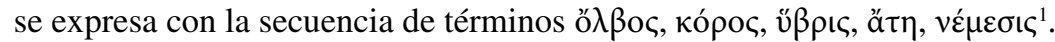

Comencemos por exponer de manera resumida ambas historias míticas, que nos servirán de punto de partida para establecer las semejanzas entre ambas.

El tesalio Ixión se casó con Día tras prometer a su suegro que le entregaría generosos regalos. Pasada la boda, Ixión se niega a entregar los regalos y prepara la muerte de Eyoneo, su suegro, con el fin de evitar la deuda. Se convierte así en el primer homicida entre los mortales. Como consecuencia de ello Ixión debe ser purificado, pero sólo Zeus aceptará eliminar la mancha de tan enorme delito; Zeus, además, le concedió el inusitado privilegio de poder acceder a su morada en el cielo y compartir su mesa junto con el resto de los dioses. De este modo Ixión alcanzó también la inmortalidad. Sin embargo, Ixión, en lugar de sentir una inmensa gratitud, correspondió a Zeus con otro delito, esta vez en la propia morada del dios: se atrevió a enamorarse de Hera e intentar violentarla. Al enterarse Zeus de los actos del tesalio, decidió imponerle un castigo. Construyó una nube a semejanza de la diosa para así hacerle víctima de un gran engaño, ya que Ixión, al no darse cuenta de las diferencias entre Hera y la nube, yació con ella, quedándose sentenciado su eterno castigo. Como consecuencia de esa unión sexual, la nube dio a luz a Centauro o a los centauros en general, según versiones ${ }^{2}$. Dada la magnitud y la excepcional gravedad del delito cometido por el ingrato Ixión, Zeus decidió imponerle un castigo también excepcional: atar a Ixión eternamente a una rueda que gira sin cesar y obligarle a reconocer, por medio de una frase que debía repetir continuamente, que se debe corresponder con gratitud a quien te haya hecho el bien.

Por lo que respecta a Tántalo, la tradición lo hace habitualmente descendiente de la unión divina entre Zeus y Plutó, y lo considera rey de Frigia y padre de Pélope y Níobe. Las fuentes antiguas suelen insistir en que sobresalía por su riqueza y fama, así como por recibir un trato de favor por parte de los dioses. Fruto de esta estrecha relación, los dioses le concedieron el privilegio de vivir junto a ellos, participar de la mesa divina y compartir con ellos el néctar y la ambrosía, adquiriendo como consecuencia de tal acto la inmortalidad. Sin embargo, Tántalo no supo corresponder con gratitud a sus benefactores; al contrario, las diversas tradiciones nos transmiten hasta un total de cinco posibles actos de ingratitud que el frigio cometió contra quienes le habían beneficiado: o bien pretendió

\footnotetext{
${ }^{1}$ Esta secuencia con diversas combinaciones se encuentra ya en época arcaica y se va repitiendo en diversos autores hasta alcanzar su plenitud en el siglo V a. C., lo que Doyle (1970, 295, n.10) describe como «' the popular Hellenic catechism' or a supposed 'age-old Ate doctrine'». Encontramos la secuencia ö $\lambda \beta$ oc, v̋ $\beta \rho \iota$, ătๆ en Hes., Op. 213-18; Sol., fr. 13, 9-16 West; Pi. P. II, 25-30; A. Pers. 816-26, y A. 750-71; y la secuencia

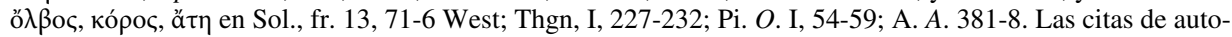
res y obras antiguas han sido abreviadas siguiendo a Rodríguez Adrados et alii, Diccionario Griego-Español (DGE), Madrid, 1980ss.

2 Entre las fuentes que nos documentan que la nube dio a luz a una raza monstruosa, los centauros, se encuentran: Critias fr. 15 a D TrGF; D. S. IV, 69; sch. in Il. I, 266-8; sch. In Lyc.1200, 34; sch. in A. R. I, 554; sch. in Luc. Pisc.12; Philostr. Im. 2, 3, 1; Seru. Ad Aen. VI, 286; Plu. Agis, 1; Ou. Met. XII, 504; Luc. Bellum Civile VI 386 ss.; Hyg. Fab. LXII. Por el contrario, siguen la versión de que la descendencia de Ixión y la nube fue únicamente Centauro, padre a su vez de los centauros cuando se unió con las yeguas de Magnesia: Pi. $P$. II, 42-47; Apollod. Epit. I, 20; Simplic. Cael. $168^{\mathrm{b}}$ (377 Heiberg); sch. in E. Ph. 1185; sch. In Od. XXI, 303; sch. in Pi. P. II, 40b.
} 
poner a prueba la clarividencia divina a través de un banquete en el cual sirvió a su hijo Pélope descuartizado; o robó el néctar y la ambrosía para dárselos a los mortales; o reveló a los hombres secretos y conversaciones que sólo concernían a los dioses; o solicitó a Zeus vivir de forma similar a un dios, abusando así de la confianza depositada en él por los dioses, o bien, por último, se cuenta que intentó engañar a Zeus negando haber recibido la custodia del perro de Creta, que había sido robado del santuario del propio dios. Como consecuencia de cualquiera de esos delitos, la mayoría de las fuentes coinciden en asignar a Tántalo dos principales castigos. Por un lado, permanecer en el Hades para siempre en medio de una laguna con el agua hasta el mentón, sufriendo sed y hambre, pero sin poderlas saciar, ni con el agua de la laguna que se aleja cada vez que él intenta alcanzarla, ni con los frutos que, próximos a sus manos, se retiran con un golpe de aire cuando prueba a cogerlos. Por otro lado, le es impuesta una roca que le tiene aterrorizado continuamente con caer sobre su cabeza.

El primer rasgo común que ambos personajes comparten, sobre el que se cimenta todo el núcleo central de cada uno de sus mitos, es su relación de $\varphi$ i $\lambda i ́ a$ con Zeus. En el preciso momento en que Zeus decide aceptar a Ixión y a Tántalo como comensales a la mesa de los dioses, ambos se convierten en sus huéspedes ( $\xi \dot{\varepsilon} v o \iota)$ y con ello, además,

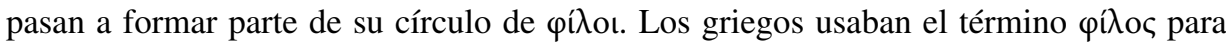
indicar una muy amplia gama de relaciones, que incluían tanto parentesco de sangre (padres, hermanos, etc.), como parentesco político (maridos y esposas), como relación social (bienhechores, beneficiados, compañeros de tribu y conciudadanos, compañeros de viajes, compañeros de armas, huéspedes, suplicantes) ${ }^{3}$. Pues la $\varphi$ i ía en la Grecia clásica, recoge M. Heath ${ }^{4}$, «no es en esencia un mero vínculo de afección y calidez emocional sino un lazo objetivo de obligación recíproca. El phílos de alguien es el hombre que está obligado a ayudar y sobre el que uno puede, o debería poder, apoyarse cuando necesita ayuda». De tal manera que la $\varphi$ ı $\lambda i ́ a$ fue finalmente concebida como una institución

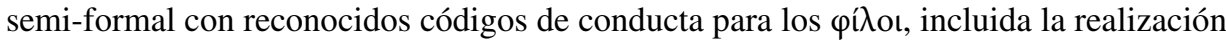
de juramentos sagrados ${ }^{5}$. Tales obligaciones debidas para los $\varphi$ í padres a hijos ${ }^{6}$. Una de estas obligaciones o condiciones básicas que ligan a los $\varphi$ í por supuesto, la lealtad. En los textos griegos del periodo clásico, es interpretada como la obligación de venir a asistir a un amigo en momentos de crisis. Faltar a esa ayuda a su vez es marca de un falso amigo. Y esa lealtad debida entre $\varphi$ í oı debe ser recíproca, ya se trate de personas unidas por lazos de parentesco, ya se trate de una relación de $\xi \varepsilon v i ́ a$

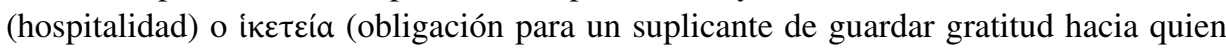
lo ha protegido). La asociación entre amistad y ayuda en las adversidades era tal que los

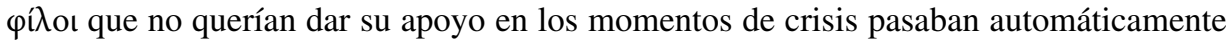
a ser considerados $\dot{\varepsilon} \chi \theta \rho o$ (enemigos). En contraste con la traición, aquellos parientes o compañeros que fielmente se mantenían al servicio de la amistad eran de por vida considerados amigos ${ }^{7}$.

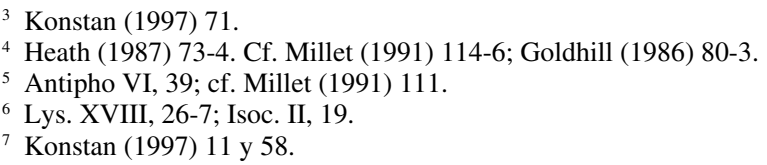


Como se ha comentado más arriba, muchos son los aspectos que puede abarcar la

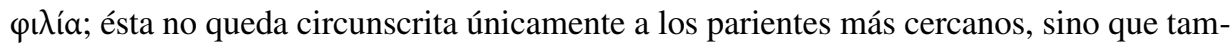

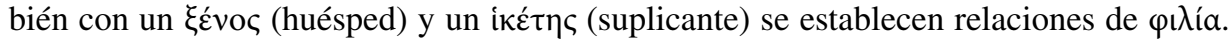
Ya leemos en los poemas homéricos ( $O d$. VIII 546-7) que «como a un hermano se ha de tratar al huésped y al suplicante». Pero mientras un pariente puede fallar al mantener sus obligaciones y aún seguir siendo pariente, por el contrario, un $\zeta \xi ́ v o \zeta$ debe corresponder a los favores recibidos si quiere continuar siéndolo.

Xápıs es el término usado en la Ética Nicomaquea (1133a-4) de Aristóteles para describir la reciprocidad que los benefactores esperan de los destinatarios de sus favores. También lo encontramos en el Discurso fúnebre que Tucídides (II, 40-4) pone en boca

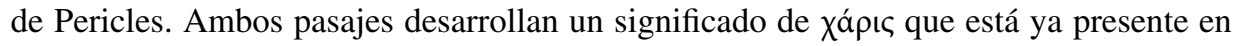
Homero": gratitud a cambio de un servicio. Y, por último, junto a este sentimiento, es necesario que los $\Phi$ í $\lambda$ or se encuentren unidos por un sentimiento de aỉ $\delta \dot{c} \varsigma$ (respeto) ${ }^{10}$, en especial el que debe profesar un suplicante por la persona a la que suplica; sólo así la relación será duradera y permanecerá incorruptible.

Por lo que respecta en concreto a nuestros personajes, Ixión y Tántalo, la relación de

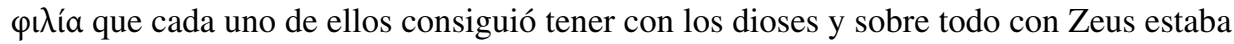

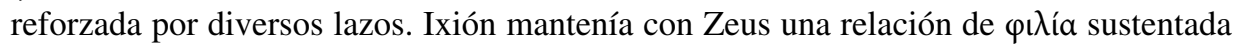
hasta por tres pilares: por un lado, había solicitado la purificación a Zeus por el asesinato de su suegro ${ }^{11}$, cuando ninguno de los hombres se atrevía a limpiar su mancha, y se

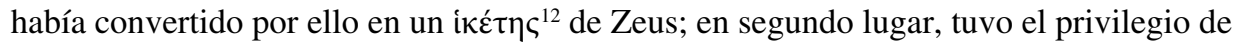
convertirse en $\xi^{\prime} v^{\prime}{ }^{13}{ }^{13}$ del rey de los dioses al compartir la mesa divina; y, por último, era hijo de Zeus, aunque ésta versión no sea la más extendida ${ }^{14}$. Por lo que respecta a Tántalo, también ostentaba doblemente el título de yí̉oc, no sólo por ser hijo del mismo Zeus, sino también porque acudía a la mesa de los dioses a degustar los manjares divinos en calidad de $\xi_{\varepsilon} v o \varsigma^{15}$, acto que era recíproco, pues también los dioses acudían a su querida Sípilo ${ }^{16}$.

La $\varphi \iota \lambda$ ía no distingue en el tratamiento de un suplicante y un huésped; en realidad la

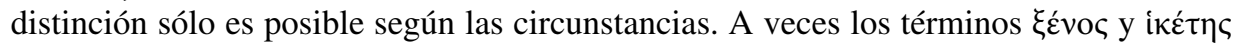
son utilizados para designar indistintamente al suplicante y al huésped, lo que nos mues-

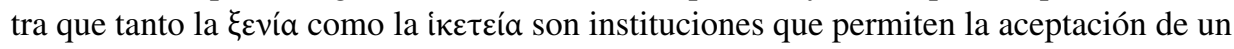

\footnotetext{
${ }^{8}$ Belfiore (2000) 7 y p. 221 n.20, donde la autora recoge una posible etimología para $\xi \dot{v}$ oৎ que liga la raíz $\xi \varepsilon v-$ con una raíz indoeuropea que significa «dar algo de manera recíproca, corresponder».

9 Il. IX 315-7; Od. IV 694-5. Un estudio en profundidad sobre la terminología de la «gratitud», no sólo en Homero sino en diversos autores comprendidos entre la época arcaica hasta el 400 a. C., puede verse en Hewitt (1927) 142-161.

${ }^{10}$ Belfiore (2000) 8 y 221 n.25; Cairns (1993). Cf. Arist. EN. 1133a2.

11 Pi. P. II, 32; A. Eu., 717-8; sch. in Pi. P. II, 57.

${ }^{12}$ Cf. D. S. IV, 69, 4; sch. in A. Eu.441; sch. in A. R. III, 62; sch. in E. Ph. 1185. También la tragedia titulada Ixión de Esquilo tendría quizá como tema principal el motivo de la súplica de Ixión a Zeus tras el asesinato de Eyoneo.

${ }^{13}$ Cf. Luc. Sac. 9; sch. in Pi. P. II, 40b; sch. in Od. XXI 303.

${ }^{14}$ Sólo en los escolios a Odisea XXI, 303 se nos cuenta que Zeus es el propio padre de Ixión. Por medio de esta estrecha vinculación de parentesco se pretende probablemente poner aún mayor énfasis en las ofensas causadas por el tesalio hacia Zeus.

15 D. S. IV, 74, 2; E. Or. 8-9; Ou., Met. VI, 172; Hyg. Fab. LXXXII, 2; Sch. in Luc.19, 29 Rabe.

16 Pi. $P$. II, 38.
} 
forastero en el grupo y que crean lazos hereditarios de obligación entre las partes hasta tal punto que los huéspedes y los suplicantes llegan a convertirse en parientes y ser tra-

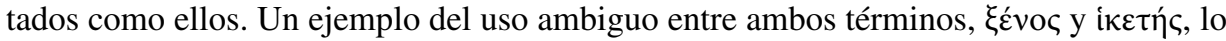
encontramos en la descripción que hace Homero en Odisea VII 154-ss. de la escena en la que Alcínoo recoge a Odiseo, sentado en el suelo, y le tributa los honores que merece: le da el mejor lugar a la mesa, lo purifica, hace una libación y le provee de comida y bebida. Alcínoo convierte así al suplicante Odiseo de $\xi \varepsilon ́ v o \varsigma$ en el sentido de «forastero» en

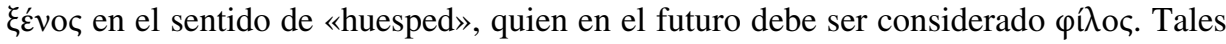
honores van acompañados de un ritual y están cargados de significativo simbolismo. En primer lugar elevar a Odiseo del suelo, tomándolo de las manos en un claro símbolo de aceptación en el grupo social. En segundo lugar, el purificarle las manos con agua y mandar realizar una libación son rituales que sirven, por supuesto, para crear un lazo de solidaridad con el huésped. Y, finalmente, el ofrecer y aceptar comida crea un vínculo ritual más de solidaridad entre los participantes en el acto ${ }^{17}$.

De manera semejante a como hace Alcínoo, también Zeus da todo lo mejor a nuestros dos personajes y el ritual que los convierte en ל́ćvo de los dioses sería muy semejante al que aquí ha sido descrito. Ambos, en efecto, aun siendo ajenos al círculo de los más allegados a Zeus, fueron escogidos de entre los mortales para participar de la mesa divina, acto que les facilitó la aceptación en el grupo de los dioses, además de que fueron premiados con el mayor de los regalos: la inmortalidad adquirida al ingerir los alimentos divinos.

Sin embargo, Ixión y Tántalo se comportaron de manera contraria a como debería

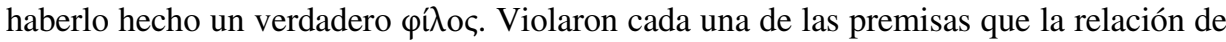
$\varphi \iota \lambda i ́ a$ imponía para que ésta perdurase ${ }^{18}$. Olvidaron que debían actuar con reciprocidad ${ }^{19}$ y estar siempre agradecidos por el enorme privilegio que Zeus les había concedido y, por el contrario, actuaron con total falta de respeto (aỉó́c): uno pretendió la unión sexual con la esposa legítima del rey de los dioses y el otro traicionó la confianza de Zeus de diversas maneras, según las diferentes versiones. Precisamente por eso, por violar una de las instituciones más importantes no escritas, perdieron la posición de privilegio que habían adquirido a través de su relación con los dioses ${ }^{20}$ y se granjearon castigos ejemplares ${ }^{21}$.

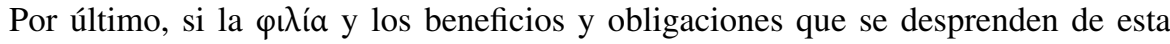
relación se heredan de padres a hijos, también son hereditarias las consecuencias que acarrean la ruptura y la violación de este vínculo. Por eso tanto los descendientes de Ixión $^{22}$, por un lado, como los de Tántalo, por otro, continuaron pagando sus culpas.

17 Gould (1973) 78-94. Cf. Kakridis (1963) 91 ss.

${ }_{18}$ Se debe recordar que Ixión tenía práctica en faltar a las normas que hacen posible la relación de $\Phi$ ı $\lambda$ ía,

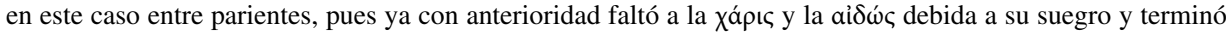
asesinándolo.

${ }^{19}$ Zeus castiga a Ixión con la repetición constante de una frase en la cual recuerda a todo el mundo que hay que corresponder con bien a quien te ha hecho el bien. Cf. Pi. P. II, 24; S. Ph., 672-3.

${ }^{20}$ Goldhill $(1986,82)$ subraya que «the relational force of philía represents a way of marking a person's position in society by his relationships».

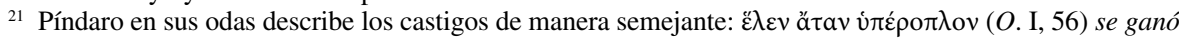

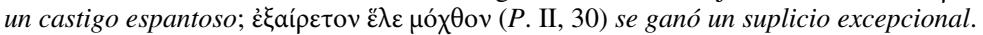

${ }^{22}$ Pirítoo, el otro hijo de Ixión, no heredó el carácter traicionero de su padre, pues pasó a la posteridad como un joven bastante sensato, leal con sus amistades, sobre todo con Teseo. Propercio II, 1, 37 lo pone como 
Los centauros, como parte del castigo de Ixión, serán dotados con un carácter indómito, salvaje y asocial; son seres monstruosos que se dejan llevar por la brutalidad y la lascivia entre dos naturalezas, sin formar parte totalmente del mundo animal ni del mundo humano, excluidos de ambos pero en relación con ellos, en una posición liminal. Por lo que respecta a los Tantálidas en general, sus destinos se encuentran plagados de enormes infortunios cuyo origen sitúan en la culpa de Tántalo.

El tratamiento literario dado a nuestros personajes demuestra claramente que se convirtieron en reconocidos prototipos de ingratitud; pero, además, en sus respectivas historias míticas podemos ver claramente plasmada, como se comentó más arriba, esa secuencia de acontecimientos típica del pensamiento arcaico y clásico griego que conduce al hombre del estado de felicidad mal digerido al estado de desgracia y al castigo subsiguiente, y que

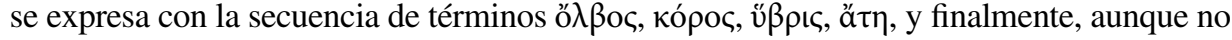
suele indicarse explícitamente así en los textos que narran el mito de nuestros personajes,

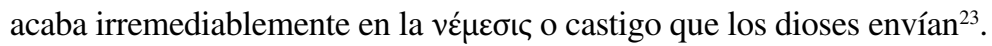

Esta cadena de ideas comienza con ő $\lambda \beta$ oc, término que indica una situación en la vida de absoluta felicidad. La dicha de Ixión o de Tántalo puede ser descrita también por el término $\pi \lambda$ oṽ $\tau$ oৎ (riqueza) ${ }^{24}$, puesto que es habitual que el estado de felicidad y prosperidad que implica ő $\lambda \beta$ $\beta$ y que alcanzan los mortales derive de las riquezas obtenidas. El estado de dicha que pueda producir ö $\lambda \beta o \varsigma$ viene intensificado por el poder de $\chi a ́ p ı \varsigma$, pues ésta es «quien crea todos los placeres para los mortales ${ }^{25}$ ».

En el caso tanto de Ixión como de Tántalo, el motivo por el cual ambos alcanzaron la felicidad hasta tal punto que les permitió llevar, en palabras de Píndaro, un $\gamma \lambda v \kappa v ̀ \varsigma$

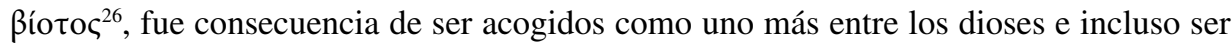

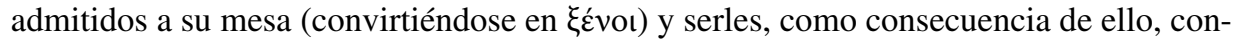
cedida la inmortalidad. Una felicidad que en el caso de Tántalo podría ser doble, puesto que, como era conocido, eran abundantes sus riquezas materiales ${ }^{27}$.

De los textos que hemos conservado en los que podemos encontrar mencionado el mito de nuestros personajes, es, sobre todo, Píndaro quien recoge en sus versos la idea de la posesión de una gran dicha. Así lo expresa en la Pítica II, 26 con el uso expreso del término ő $\lambda \beta o \varsigma$ para referirse a Ixión:

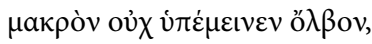

no soportó una dicha duradera

ejemplo de lealtad a la amistad dejando así bien claro la oposición entre el comportamiento de su padre y el suyo.

${ }^{23}$ Siendo esta secuencia una de las bases del acontecer trágico, no es de extrañar que el mito de nuestros personajes fuese muy aprovechado como tema principal de tragedias, pues tenemos documentados varios Ixiones y Tántalos, o para aparecer en ellas como contraejemplo por su comportamiento impío. También sirvieron para ejemplificar comportamientos ingratos y la necesidad de no transgredir la propia medida, tal y como podemos ver en las pindáricas Pítica II y Olímpica I.

${ }^{24}$ Cf. Sol., fr. 13, 9-16 West.

25 Pi. O. I, 30. Cf. Fisher (1992) 240.

${ }^{26} P$. II, 26.

27 Su riqueza es mencionada por autores como Isócrates V, 144, 2 y Platón Euthphr. 11e, y el hecho de

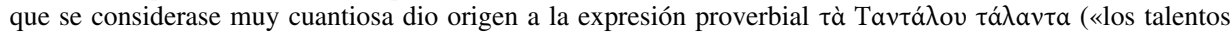
de Tántalo»), recogida por Plutarco, Erótico 759 F, 4 y brillantemente estudiada por Bühler (1999) 273-80. 
Y en la Olímpica I, 56 con el mismo término, esta vez referido a Tántalo:

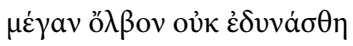

no pudo digerir su gran fortuna

Aunque ya no con el término ő $\lambda \beta$ oৎ como tal para referirse al estado de fortuna que tuvieron el privilegio de alcanzar Ixión y Tántalo, sí existen en las diversas fuentes antiguas alusiones a la felicidad alcanzada por ambos. Por ejemplo, Eurípides ${ }^{28}$ califica a Tántalo de $\mu$ akápıoc, un término especialmente significativo, ya que es el que se especia-

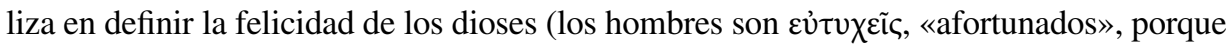
su dicha depende de los dioses), y también Diodoro Sículo se refiere a la felicidad de Tántalo, aportándonos una larga lista de motivos que explican bien que Tántalo pudiera ser considerado un mortal extraordinariamente dichoso:

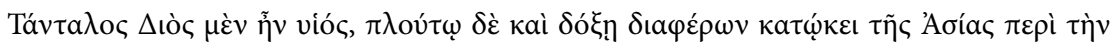

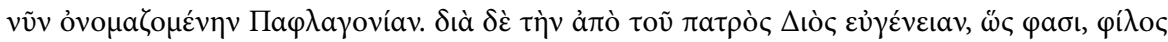

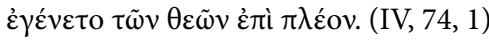

Tántalo era hijo de Zeus; sobresalía por su riqueza y por su fama, y habitaba en la región de Asia que actualmente se llama Paflagonia. A causa de su noble cuna al tener como padre a Zeus, fue objeto, según dicen, de un especial afecto de los dioses.

Sin embargo, Ixión y Tántalo se muestran incapaces de disfrutar de la condición privilegiada en la que se encontraban, lo que deriva en la superación de los límites humanos, el castigo y la ruina. En efecto, no fueron capaces de «digerir» su extraordinaria

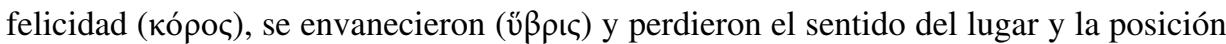
en que se hallaban. De esta manera quedaría corroborado que el ő $\lambda \beta$ oৎ de los mortales no está destinado a durar mucho, si se tiene en abundancia.

Es propio de la condición humana el ser incapaz de resistir y comportarse como se esperaría de su condición; así lo manifiesta, para Tántalo, Eurípides:

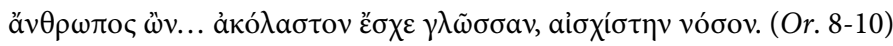

aun siendo mortal... no refrenó su lengua, el más vergonzoso vicio.

o, de nuevo, Diodoro Sículo:

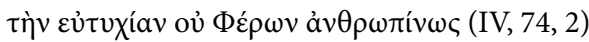

como humano que era, no estuvo a la altura de su fortuna

donde se recoge la idea de que los mortales no saben mantener su felicidad.

Salvo el testimonio del v. 56 de la Olímpica I de Píndaro, en el cual se usa expresamente el término kópos para referirse al «hartazgo» de Tántalo, no nos ha llegado ningún otro texto en que se use este vocablo referido a Ixión o a Tántalo. Sin embargo, la idea de la «mala digestión de la felicidad» se encuentra implícita en algunas expresiones análogas. Tal es el caso del v. 26 de la Pítica II referido a Ixión, donde el concepto se

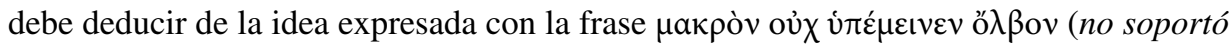

28 Or. 4-5. 
una dicha duradera $)^{29}$. También en el perdido poema épico Regresos (fr. 10 Bernabé) se dice de Tántalo:

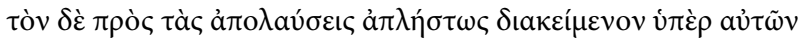

en una disposición tan insaciable para los goces como tenía.

Los efectos que produce el dejarse llevar por un estado de saciedad y envanecimiento son los siguientes: la incapacidad de controlarse, no reconocer los límites apropiados para el hombre y, por ignorancia de ellos, no darse cuenta de la medida de las $\operatorname{cosas}^{30}$; todo ello es consecuencia de una ceguera (ă $\tau \eta)$ que imposibilita darse cuenta de que se es víctima de un engaño y/o castigo.

La unión de los dos primeros efectos anteriormente citados produce en los morta-

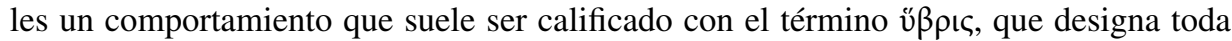
aquella arrogancia que sobrepasa los límites de lo lícito ${ }^{31}$. Fisher ${ }^{32}$ describe este concepto de manera genérica así (parafraseo): űßpıs es esencialmente un serio ataque a la honra de otro, y conduce a la ira y a los intentos de venganza. " $\Upsilon \beta \rho \iota \varsigma$ es a menudo, pero no necesariamente, un acto de violencia; es en esencia un acto deliberado de infligir una deshonra por el mero hecho de sentirse superior. $\Upsilon \beta \rho \iota \varsigma$, frecuentemente, se presenta, en un individuo o en humanos en general, bajo la apariencia de actos específicos o un comportamiento general contra otros, más que actitudes. A veces el acto de üßpıৎ se produce

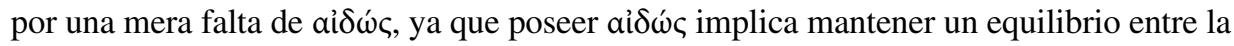
propia $\tau \iota \mu$ (el «honor», en el sentido de la valoración que los demás le otorgan a uno) y la de los demás. Otras veces, las ofensas de üßpıৎ tienen que ver con formas de asaltos físicos, sexuales o verbales que demuestran el desprecio del que lo hace por su víctima, pero también regularmente denota maneras de comportarse personalmente que demuestran una idea exagerada de la importancia que se da uno mismo y el correspondiente desprecio por las reclamaciones de otros ${ }^{33}$.

Todos estos comportamientos pueden ir dirigidos de un hombre contra otros hombres o, lo que sería una ofensa mayor, de un hombre contra los dioses. Por lo que respecta a la ofensa entre hombres, en sociedades como la antigua (y moderna) Grecia, donde el honor individual era un valor de importancia universal, la ü $\rho ı \varsigma$ tiene un considerable significado moral y social. Puesto que un honor ultrajado tenía consecuencias perjudiciales y potencialmente violentas, algunos actos de üßpı se interpretaron a menudo como causa de agitaciones políticas y de guerras, por lo que las comunidades sintieron la fuerte necesidad de restringir estos actos a través de leyes y por medio de sanciones.

Cuando la űßpıৎ va dirigida contra los dioses, es entendida ésta, de manera especial, como una falta religiosa, un delito de impiedad. Se entiende como acto de üßpıৎ contra los dioses toda aquella acción, palabra e, incluso, pensamiento en el que el hombre olvida la limitaciones propias de su naturaleza mortal, busca adquirir los atributos de los dioses, compite con ellos o se jacta confiadamente; es, en definitiva, toda acción o palabra

\footnotetext{
29 Burton (1962) 116.

${ }^{30}$ Fisher (1992) 237.

31 Lesky (1973) 134.

${ }^{32}$ Fisher (1992) 1.

${ }^{33}$ Gregory (2005) 313.
} 
con la que un hombre atenta contra la hospitalidad de los dioses o, incluso, despierta sus celos con independencia de que alguien se vea afectado. A veces no es más que la posesión de una inmensa buena fortuna lo que ofende a los dioses ${ }^{34}$. La existencia del hombre se halla, por el mero hecho de ser hombre, amenazada constantemente por parte de los dioses a través de aquella tentación de üßpıৎ, que en forma de obcecación y arrogancia sobreviene al ser humano ${ }^{35}$.

En el caso de Ixión y Tántalo sus delitos de üßpıs estaban dirigidos contra los dioses. Este mal comportamiento surge como resultado de dejarse llevar más allá de la propia mesura y olvidarse de los límites de la mortalidad, consecuencia directa de la gran prosperidad que alcanzaron y la confianza que tenían con los dioses, y lo manifiestan de la siguiente manera:

Ixión, tal y como se narra en su mito, se comportó como un v́ßpı tń c cuando pensó que, aun siendo mortal, podía disfrutar de la esposa del rey de los dioses. Esto es con toda seguridad el resultado de la mala «digestión» (кó $о \varsigma$ ) de la prosperidad que había alcanzado (ő $\lambda \beta$ oৎ), y ello lo muestra en un acto de «arrogante desvarío» ${ }^{36}$, un acto en el cual él presume de hacer más de lo que le corresponde a su categoría mortal. Por tan-

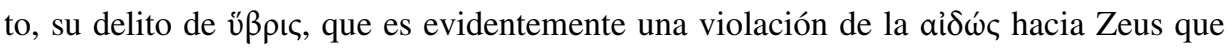

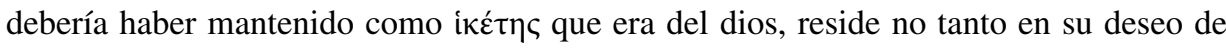
propasarse con Hera, pues ella tiene un fuerte carácter y fácilmente habría sido capaz de reponer su honor, sino que la ofensa va directamente hacia Zeus, su marido, por medio de un descarado y gratuito insulto, además de que hizo tambalear la estabilización del orden moral. Pues, aunque también Paris tomó a la esposa del hombre que le había ofrecido generosamente su hospitalidad y con ello faltó a todas y cada una de las premisas que rigen la $\varphi$ i ía, en el caso de Ixión el delito es aún mayor, pues el deshonrado marido es el soberano de los dioses y hombres, quien estableció proteger las leyes de la hospitalidad y del matrimonio ${ }^{37}$.

El término üßpıs lo encontramos expresado explícitamente para referirse a Ixión en la pindárica Pítica II, 28. Posteriormente no lo volvemos a encontrar entre las fuentes

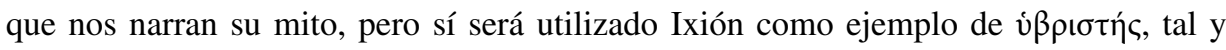
como se puede apreciar en un pasaje de la Antígona de Sófocles (vv. 134-7), donde Capaneo es comparado con el tesalio por albergar una actitud semejante ${ }^{38}$. En estos versos

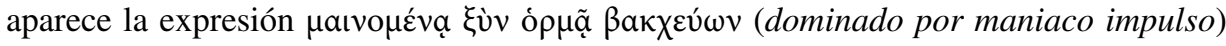
que, aunque es evidente que en el contexto en el que se insertan estas palabras se refieren a Capaneo, sirven como punto en común entre él e Ixión.

Por lo que respecta a Tántalo, ya ha sido expuesto que existe en la tradición hasta un total de cinco tipos de delitos diferentes por los cuales Zeus se vio obligado a condenar

\footnotetext{
34 Fisher (1992) 3-4.

35 Lesky (1973) 136.

36 Pi. P. II, 28.

${ }^{37}$ Fisher (1992) 237-8.

38 González Ruz (2013) 335-8.
} 
a uno de sus $\varphi$ í̉oı. Lo importante es que, a excepción de su complicidad en el robo del perro de Creta, todos se caracterizan por ser delitos de űßpıৎ contra los dioses:

- Si pensamos en el delito del banquete caníbal, vemos que la actuación de Tántalo está cargada de vanidad. Su obsesión por querer igualar a los dioses a la hora de presentarles manjares a sus mesas, le lleva a la perversión de servir las carnes de su hijo como si de una exquisitez se tratase. Conocedor de que no sería posible igualarlos, al menos intenta que, si caen en su trampa, queden rebajados a su nivel. Así queda demostrada la perversión de Tántalo y la forma perversa que adopta su vanidad ${ }^{39}$.

- Si tomamos como ofensa la de hacer partícipes a sus compañeros mortales de la comida y bebida divina ${ }^{40}$, debemos pensar que de la misma manera constituye una gran violación a la altura del crimen de servir a su hijo a sus huéspedes

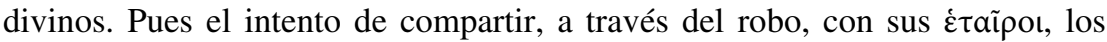
privilegios que le permitían disfrutar eternamente de los festejos divinos es una gran ofensa para los dioses, ya que de este modo Tántalo se arroga un poder que no le corresponde e intenta pasar por encima de aquellos a los que debe una especial obligación al deberles favores que exigen reciprocidad ${ }^{41}$.

- Por último, nos quedaría la versión en la que el delito de Tántalo sería haber pretendido vivir de manera semejante a los dioses. Una muestra más de la insaciable disposición hacia los goces que poseía Tántalo.

Todas las versiones de las causas del castigo de Tántalo tienen puntos en común: el abuso por parte de Tántalo de la confianza y hospitalidad de los dioses, a partir de su posición privilegiada como compañero de mesa de ellos, y la interrupción de la articulación del cosmos, al desbaratar los límites entre bestias, hombres y dioses. Esta transgresión de los límites que como hombre posee, queriendo ser más semejante a los dioses de lo que era apropiado, conlleva un castigo que llega como consecuencia de intentar traspasar sus competencias y querer ser como los dioses ${ }^{42}$.

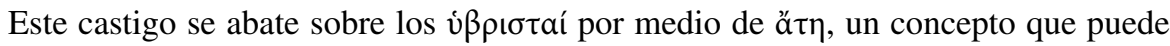
ser interpretado en varios sentidos. Habitualmente puede tener el valor de «ruina, destrucción o desastre», tal y como aparece en el v. 770 del Agamenón de Esquilo ${ }^{43}$. Pero en su sentido original designa una metafórica ceguera o locura ${ }^{44}$, que, en efecto, conduce a la ruina al impedir que la persona afectada razone convenientemente y se dé cuenta de lo que está haciendo.

\footnotetext{
${ }^{39}$ Diels (1966) 60-1.

${ }^{40}$ En este apartado incluiríamos el delito que Tántalo habría cometido al divulgar los secretos divinos a los mortales. Pues ambas versiones son entendidas como compartir con los hombres algo que era propio de los dioses y que a la raza humana le estaba vetado. Estos dos motivos diferentes a priori pueden entenderse como una misma trasgresión consistente en haber distribuido un don que no puede o no debe conocer difusión para seguir así manteniendo la irreducible distancia que separa y debe separar a los hombres de los dioses, fundada sobre la mortalidad humana.

${ }^{41}$ Fisher (1992) 240-1.

${ }^{42}$ Cf. Sourvinou-Inwood (1986) 45.

43 Doyle (1970) 297-300.

${ }^{44}$ Con el sentido de ceguera o locura también en Hes, Op. 213-18; Sol. fr. 13, 9-16 y 71-76 West; A., Pers. 816-26 y A. 381-88.
} 
Es evidente que, en el caso de Ixión, la destrucción que se abate sobre él viene en forma de ceguera y/o locura, aquella que le imposibilita ver el engaño al que va a ser sometido por parte de Zeus, la nube que él confunde con la diosa Hera. Así lo transmite Píndaro en $P$. II, 28:

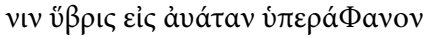

$$
\begin{aligned}
& \tilde{\omega} \rho \sigma \varepsilon \nu \\
& \text { su insolencia lo empujó a un arrogante desvarío }
\end{aligned}
$$

Por lo que respecta a Tántalo, no nos ha llegado ningún texto en el que se mencione expresamente el término ä $\rceil \eta$ referido a él. Pero es evidente que se debe deducir de los actos delictivos que llevó a cabo contra los dioses.

Un rasgo importante de ắn y el daño que ésta produce es su inevitabilidad. Es más, la primera víctima del daño de la locura es el propio enloquecido que, como es bien sabido, en el caso de nuestros personajes les llevó a suplicios excepcionales. Pero en un segundo plano, arruina también a su familia, incluso su mismo futuro generacional, pues sus descendientes serán parte de ese castigo. Por lo que respecta a los hijos de Ixión, los centauros, que manifiestan la misma üßpıs erótica que su padre, como hemos relatado más arriba, serán condenados a vivir en la marginalidad entre lo humano y lo bestial. Los descendientes de Tántalo, sobrellevarán a sus espaldas si no la certeza, al menos la intuición de que gran parte de sus desgracias son consecuencia directa de la herencia de su antepasado. Así lo expresa Séneca en su obra Tiestes; sobre esta idea basa el comienzo de su obra:

Ta. Me pati poenas decet,

non esse poenam. (...)

ducam in horrendum nefas

auus nepotes? vv. 83-90.

Tántalo: Lo que a mí me corresponde es sufrir un castigo, no ser yo un castigo (...) ¿Voy a conducir a una horrenda impiedad a mis nietos yo, su abuelo?

En palabras de Oates ${ }^{45}$ : «el resultado de las acciones del hombre vive después de él» para bien o para mal.

Y, por último, para finalizar de esta manera con la cadena de sucesos que estructura la composición de los mitos de Ixión y de Tántalo, en su caso, además de la átๆ, que ya es un castigo en sí mismo, los dioses decidieron imponer sobre ellos castigos físicos y psicológicos ( $v \varepsilon ́ \mu \varepsilon \sigma \iota \varsigma)$ que sirviesen de lección moral no sólo a ellos sino también a quienes estuviesen en disposición de comportarse a su semejanza. Sólo así, por medio del dolor que de ello se origina, el hombre comprende y reconoce la eterna validez de las leyes divinas. La ardiente voluntad del hombre tropieza con un orden grande, basado en lo divino, que le señala sus límites y hace que su caída sea significativamente un testimonio de dicho orden ${ }^{46}$.

El término vé $\varepsilon \varepsilon \sigma \varsigma \varsigma$ no aparece en ninguno de los pasajes que la tradición nos ha legado acerca de los mitos de Ixión y Tántalo; no obstante, se intuye fácilmente el concepto

\footnotetext{
45 Oates (1963) 379.

${ }^{46}$ Fisher (1992) 3 y 259-61. Cf. Gregory (ed.) (2005) 314-5.
} 
en infinidad de citas en las que se mencionan o se describen con profusión de detalles los castigos que Zeus decretó para nuestros personajes. Los más significativos de todos son aquellos en los que se hace referencia al castigo impuesto a Ixión, especialmente aquellos en los que se especifica que, además de sufrir toda una eternidad los giros incansables de una rueda, debe por mandato divino proclamar a los mortales la moral recabada

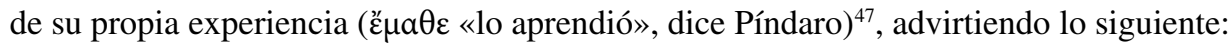

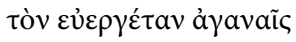

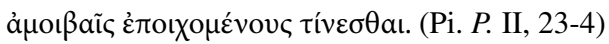

Honrad al bienhechor, pagándole con gentil correspondencia.

A Tántalo, según versiones, le es impuesta una roca que le tiene aterrorizado continuamente con caer sobre su cabeza o debe permanecer en medio de una laguna con el agua hasta el mentón, sufriendo sed y hambre, pero sin poderlas saciar.

Zeus no eligió arbitrariamente los castigos para nuestros protagonistas, sino que son reflejo de parte de algo que hicieron mal. Por un lado, el castigo de Ixión conlleva la moraleja de enseñar a todo aquel que lo vea o escuche que se debe actuar conforme a las leyes que marca la $\varphi \imath \lambda$ ía. Por otro lado, el castigo de la sed y el hambre de Tántalo conlle-

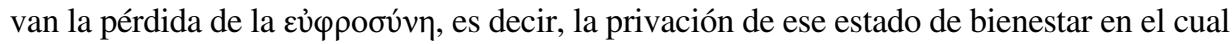
se hartaba a disfrutar de la buena comida y bebida ${ }^{48}$. Ambos por tanto no sólo son claros ejemplos de lo que en vida no se debe hacer (por eso sirven como contraejemplos), sino que también, una vez en el Hades, lugar donde la mayoría de fuentes sitúan a nuestros personajes, sus castigos siguen siendo un recuerdo de las malas acciones cometidas por cada uno de ellos y se convierten, por esto, en el prototipo de castigados eternos.

Todo aquello que sucedió a Ixión y a Tántalo puede resumirse con la cita de un pasaje de Solón, en el cual queda claro cómo el comportamiento de ambos es común a todos aquellos mortales que se ven desbordados por una situación que les supera porque ellos han superado sus límites:

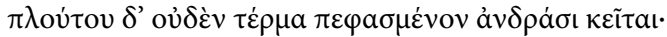

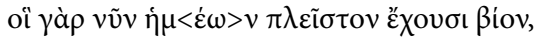

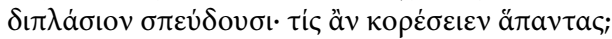

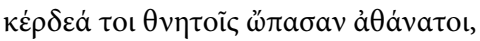

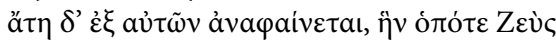

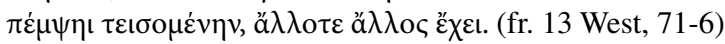

De la riqueza no hay término alguno fijado a los hombres;

pues ahora entre nosotros quien más bienes tiene

el doble se afana. ¿Quién puede saciarlos a todos?

Las ganancias, de cierto, las dan a los hombres los dioses,

y de ellas procede el desastre, que Zeus de cuando en cuando

envía como castigo, y ya uno, ya otro lo recibe ${ }^{49}$.

\footnotetext{
${ }^{47}$ Pi. $P$. II, 25.

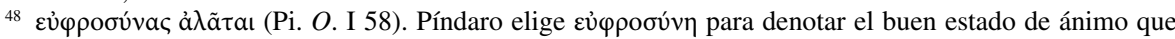
está presente en los banquetes así como la bebida y el alborozo de la fiesta de celebración de la victoria. Cf. $P$. IV, 129; N. IV, 1. Véanse Gentili et alii (1995) 464; Farnell (1932) ad v. 58; Gerber (1982) ad v. 58.

49 Traducción de García Gual (1980).
} 


\section{BIBLIOGRAFÍA}

Belfiore, E. S., 2000. Murder among friends. Violation of «Philia» in Greek tragedy, Nueva York - Oxford.

BüHLER, W., 1999. Zenobius Athoi proverbia. 5, Libri secundi proverbia 41-108, Göttingen.

Burton, R. W. B., 1962. Pindar's Pythian Odes, Oxford.

CAIRns, D. L., 1993. Aidôs. The psychology and Ethics of Honour and Shame in Ancient Greek Literature, Oxford.

DiELs, P., 1966. Le Symbolisme dans la mythologie grecque, París.

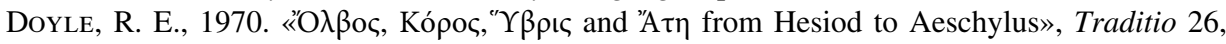
293-303.

FARNell, L. R., 1932. Critical commentary to the works of Pindar, Londres (reimpr. Amsterdam 1961).

Fisher, N. R. E., 1992. Hybris, Warminster.

García Gual, C., 1980. Antología de la poesía lírica griega, siglos VII-IV a. C., Madrid.

Gentili, B. et alii, 1995. Pindaro, Le Pitiche, Milán.

Gerber, D. E., 1982. Pindar's Olympian one: A commentary, Toronto.

Goldhill, S. D., 1986. Reading Greek Tragedy, Cambridge.

González Ruz, M. G., 2013. Paradigmas de ingratitud. Ixión y Tántalo en las literaturas griega y latina, Tesis de la Universidad Complutense de Madrid.

GOULD, J., 1973. «HIKETEIA», JHS 93, 74-103.

Gregory, J. (ed.), 2005. A Companion to Greek Tragedy, Malden - Oxford.

Heath, M., 1987. The Poetics of Greek Tragedy, Londres.

HewitT, J. W., 1927. «The terminology of 'Gratitude' in Greek», CPh 22, 142-161.

KAKRIDIs, H, J., 1963. La notion de l'amitié et de l'hospitalité chez Homère, Salónica.

Konstan, D., 1996. Friendship in the Classical World, Cambridge.

LESKY, A., 1973. La tragedia griega, Barcelona.

Millett, P., 1991. Lending and Borrowing in Ancient Athens, Cambridge.

OAtes, J. F., 1963. «Pindar's Second Pythian Ode», AJPh 84,377-389.

Sourvinou-Inwood, C., 1986. «Crime and punishment. Tityos, Tantalos and Sisyphos in Odyssea $11 »$, BICS $33,37-58$. 
